\title{
DEVELOPING A RELIABLE AND VALID QUESTIONNAIRE ON COURSES' EXPERIENCES OF UNIVERSITY STUDENTS IN PAKISTAN
}

\section{Dr. Muhammad Arshad ${ }^{1}$, Dr. Ishrat Siddiqa Lodhi ${ }^{2}$, Dr. Muhammad Shakir ${ }^{3}$}

\begin{abstract}
This study was designed to make a self-structured survey questionnaire reliable and valid. It is considered that in a study a precise, reliable and valid instrumentation is important step to collect the required information for that study. Therefore, a self-made questionnaire that was designed to measure university students' satisfaction on their courses experiences at university level in Pakistan was made reliable and valid. Reliability of the questionnaire was assured by using Cronbach's formula on finding alpha values (internal consistency method) and inter-item correlation (relationship among items). Validity was assured (convergent and concurrent) by finding correlation values among items using Spearman's formula. It took three steps to bring the questionnaire into final shape. In the final version of the questionnaire after deleting one statement and changing the sequence of another all the values of remaining items were found within acceptable range. Thus, the instrument after becoming reliable and valid was ready to use in a study only in Pakistan.
\end{abstract}

Keywords: Research tool, Reliable, Valid, Bias-less, Spearman's correlation

\footnotetext{
${ }^{1} \mathrm{PhD}$ Scholar, Department of Education, The Islamia University of Bahawalpur, arshad06@gmail.com

${ }^{2}$ Director Academics, Higher Education Commission (HEC) Pakistan, ishratsiddiqalodhi@gmail.com

${ }^{3}$ Lecturer, Department of Educational Training, The Islamia University of Bahawalpur,shakir.iub@gmail.com
} 


\section{Introduction}

A questionnaire was developed to measure students' satisfaction on provision of courses for learning during their stay in the university. Now a days, it has become a common practice at university level to evaluate program outcomes with the help of selfreported questionnaire to see to what extent students were satisfied about learning facilities provided to them. Because it is considered that students' satisfaction plays vital role to achieve the desired goals for educational stakeholders. Students' satisfaction is also a source to increase the repute and rank of an institution because students' satisfaction resulted in motivation among them to learn. While, satisfaction is a matter of perception of learning environment therefore can be said a predictor of better learning outcomes (Usman, 2010; Huang, 2007). Thus, it becomes the responsibility of a university to create learning environment for the students by providing their desired educational facilities (Aldridge \& Rowley, 1998).

Thus students' satisfaction circles around the quality of the facilities provided in the institution during their study period. In a study Marzo-Navarro, Pedraja-Iglesias \& Pilar Rivera-Torres (2005) find out that courses and curriculum contents provided to the students have very important role in satisfying them.

Due to reach of information from all over the world under finger stroke created the thirst of better for the users. Thus to attract the users that are students has created a competition among universities to attract them towards them on providing them quality education. Thus students' opinions have caught weightage and become a strong indicator of quality education. Therefore, to collect reliable information it is also necessary to have a measuring instrument that is reliable and valid to measure what is to be measured. That this study will do.

\section{Review of Literature}

According to Kember \& Leung (2009) and Fry, Ketteridge \& Marshall (2004) the skills needed at higher education level are called 'skills for the world of work'. Literature and researches conducted in this area especially in Pakistani scenario pointed 
out capabilities needed for university teachers as well as students are as discussed below;

\subsection{Reflective Teaching skill}

In this rapidly changing world new techniques and skills are being introduced to perform a task up to the standards during professional carrier of a worker. Among these is reflective thinking skill that is fertile to face the changes. Reflection with selfassessment is a meaningful process that can lead to learning from experiences, yet have different purposes and goals. Reflection is said a mental process with purpose and/or outcome in which manipulation of meaning is applied to relatively complicated or unstructured ideas in learning or to problems for which there is no obvious solution. To reflect while teaching is a dualism that challenges may, yet though practice these tasks can be realized simultaneously; to reflect the activity is something that improves with effort. It can be said that reflection is a state of mind, an ongoing constituent of practice.

\subsection{Analytical Skill}

Analytical skill is the second step to reach decision with rational thinking skill. It is the ability to reason rationally before reaching decision (Adair, 2007). In every step of a person's life, one has to take decision but especially at workplace it is crucially needed. Analytical reasoning skill helps a person to reach the roots of the situation after analysing it from different angles. It also helps to envisage a thing in a given situation from different angles by breaking down into smaller parts. According to Fry, Ketteridge \& Marshall (2004) analytical skill helps to identify and constitutes that builds the real thing that may be a problem.

\subsection{Critical Thinking Skill}

The swiftly changing world put pressure on our life to respond it in every aspect of our life realities. These realities are becoming increasingly complex and put pressure to profound thinking to resolve these problems. At higher education level it is needed to develop critical thinking skills among graduates to face and also is required a radically different form of thinking skills to 
resolve the complex problems (Fry, Ketteridge \& Marshall, 2004). A skilled teacher can make learning interesting by giving daily life example to produce critical skill that would be create students' interest for learning and mental satisfaction.

\subsection{Creative Skill}

Every job now a day desires creative ability to meet challenges of the projects on one's workplace. It is all due to the rate of changes spearheaded by technology, involving lifestyles, beliefs, and knowledge. It is providing a better integrated beliefs, values, knowledge, labour and resources (Csikzentmihalyi, 2006). The ability to imagine for inventing new world of and for oneself is a person's actual asset as well as all types of our achievements. But for creating an innovative culture its' relevance to education is necessary to get a larger corporation in an organization and it is a challenge for the institution and for academia as well. According to Jackson (2006) a teacher can encourage students with these activities:

- Fluency in thinking different ideas

- Flexibility of thinking different ways of completion of a job

- Originality of thoughts that means ideas purely of one thinker's

- Elaboration of ideas in details and its all aspects.

\subsection{Life-Long Learning Skill}

It is education that along with other opportunities promotes a productive citizenry and economically underprivileged sections of society. According to Kember and Leung (2009) all the skills developed among university graduates are to build habit of life-long learning. People need to learn work skills and to learn to relate to others, live in societies, communities and in families to become more caring and supportive. Education provides opportunity to equip a person with skills to compete the world in changing circumstances by continuous learning. It is based on four pillars of learning;

- Learning to know; learning how to learn other than within 
specific sets of knowledge.

- Learning to do; developing the competence and ability to respond new challenges and new demands of life.

- Learning to live together; create flexibility and ability to resolve conflicts peacefully, nurturing community potential

- Learning to be; learning to contribute for community development, aesthetic and diverse cultural appreciation, and prove one's skills in practical life.

\subsection{Communication Skill}

Almost all job descriptions now stress on communication skills. Communicative competence involves producing language correctly as well as to use it for particular purpose in a contextually appropriate way. It is a source of conveying our inner-self and purposes to others. There are certain ways of communication but the most effective one is verbal communication. Fluency and acceptable language is the primary goal of communication. In it, proper words of a language are source by which a person communicates to others. Communication competency also creates confidence in a person. During teaching communication is crucially needed to transmit knowledge to others. Thus a teacher should equip the students with this skill in the best way. It also helps to cater with emerging changes and challenges in the worst problem and the best solution (Mangubhai, Marland, Dashwood \& Son, 2007). In this respect teacher can use different methods of developing communication skill among graduates.

\subsection{Population and sample:}

\section{Research Methodology}

As the major purpose of this study was to validate this tool so population included students of The Islamia University, Bahawalpur (IUB) studying in the disciplines of social sciences in final year. Later on the students of three departments were considered for this study; social work, psychology and education. Because according to Field (2005) to find out the values of reliability 120 survey questionnaires are enough. While in this work 234 questionnaires were got filled. 


\subsection{Conceptual framework of questionnaire}

The researches conducted in this area and environment of Pakistani universities pointed out following aspects in the courses are important;

i) choices in the courses, ii) availability of learning material iii) clarity to understand iv) organization of contents $v$ ) relevancy of curriculum contents to the objectives vi) academic benefits of the course (skill development elements; reflective thinking skills, critical thinking, problem solving, analytical skills, lifelong learning, confidence and communication) vii) motivational elements viii) autonomous learner, ix) application of ICT

\subsection{Refinement of the Research Tool}

The following procedure was adopted to make the instrument reliable and valid. It took three steps to finalize the tool.

\subsubsection{Initial Scale}

A pool of 36 (thirty six) items' questionnaire was developed. Each item was rated at 5-point Likert-scale having two major options; one on satisfaction and other on importance. Thus, a respondent has to fill two options, one on satisfaction and other on importance. This questionnaire was distributed among faculty members of education department, The Islamia University of Bahawalpur, Pakistan for suggestions for improvement. The help was also sought out from the department of psychology due to having behavioral and cognitive nature of the questionnaire. It was discussed with the fellow researchers. On a fixed day and time researchers reached in a room and the questionnaire was put into arena item-wise for discussion. The researcher explained the objectives of the study, format as well as the statements where needed. After a long and progressive discussion the items were reduced to 22 (twenty two) in this tool.

The necessary changes were made in the light of the suggestions of the faculty members. Ranking order was from lower order to higher order. Because it is considered that in Likert-scale ranking order from lower to higher values enable the respondents to identify, compare and select the suitable choice (Utts \& Heckard, 2004; Creswell, 2009; Cohen, Manion \& Morrison, 2011). 
The initial version of questionnaire having 22 items was distributed among the students of MA Final (session 2011-12) social work, education and psychology department in the Islamia University of Bahawalpur, Pakistan to check the suitability of the instrument. The total number of 234 questionnaires were distributed among the students. The collected data were sorted out and found that, only $39.45 \%$ questionnaires were completely filled while $60.55 \%$ were half or less than half-filled, in spite of explaining it item-wise to the respondents. It was then tabulated in SPSS-16 for further screening, refinement and checking its reliability and validity. The reliability of the initial instrument was calculated by Cronbach's co-efficient $\alpha$ value (internal consistency method) that was $<0.50$ thus not appreciating as well as acceptable. On finding this alarming situation fifteen (15) participant students were individually interviewed to determine the difficulties in understanding statements, language of the statements, vocabulary, or any other problem faced by them in the questionnaire. All the interviewees pointed out that major problem was on two main options for one statement, 5-point scale and in understanding language of a few statements.

Thus, it was needed to modify the research instrument. This format of the questionnaire was adopted from Douglas, Douglas \& Barnes (2006) who conducted this study in United Kingdom. According to Cohen, Manion \& Morrison (2012) an instrument developed, tested and validated in a country may not be suitable in other country having different culture. A research tool should be put the respondents in a proper frame of mind according to their psychology and clear to understand for answering the questions (Rubin \& Babbie 2005; Singh \& Bajpai, 2006; Fraenkle, Wallen \& Hyun, 2006).

Thus based on the difficulties pointed out by the respondents during interview as well as in preliminary analysis, the results were discussed with the supervisor as well as other experts. Now the initial research instrument was modified in the light of the suggestions by the experts and difficulties pointed out by the interviewees to make it culture relevant and respondents' friendly. All the statements were 
revised, explained and language was made easier. The second major change brought in this tool was that 5-point scale was changed to 3point Likert-scale.

\subsubsection{Interim Scale}

The initial questionnaire was changed into interim questionnaire having 21 statements. This questionnaire with three point Likert-scales was again tried out in three universities; University of Education, Lahore; Abdulwali Khan University, Mardan; and Hazara University, Mansehra. The collected data were then used to check the reliability and validity. Total number of 190 questionnaires were got filled and ready for further process. The data were tabulated in SPSS-16 and reliability by Cronbach's Alpha internal consistency method was applied. The overall $\alpha$-value of the tool was found 0.947 and can be increased to 0.957 by deleting some of the statements. Now reliability of individual items was calculated and two items were found to be deleted due to having low values than acceptable range while two statements needed replacement in order to be become more reliable. After making necessary changes again its reliability and validity was calculated in a comprehensive way to reduce errors and biasness from the instrument that is mentioned below.

\subsubsection{Final Version of the Instrument}

The final version of SSLQ-F (students' satisfaction level scale final) has 19 items. The division of the items with sequence in the questionnaire in each aspect is mentioned in the following diagram;

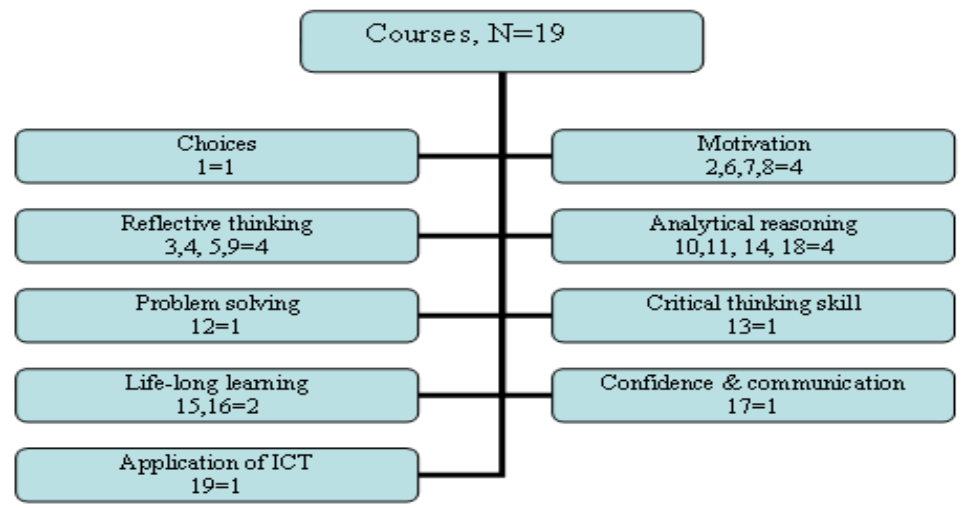


The items of one aspect of the courses are put randomly either to put in a sequence to observe the reliability as the statements on analytical skill producing elements are in number 10,11, 14 and 18 and same is done with other aspects of courses.

\subsection{Statistical Analysis}

All the statistical analysis was performed with the help of SPSS-17. There were two major options in this questionnaire each with three options and were valued as;

Not at all satisfactory $=1$, moderately satisfactory $=2$ and extremely satisfactory $=3$

Not at all important $=1$, moderately important $=2$, and extremely important $=3$

\subsubsection{Measuring Reliability}

Reliability measures the consistency of the research tool. Reliability is the degree to which the given concept of measurement produces the same results with the same tool (Corbetta, 2003; Best \& Kahan, 2006). Reliability is also said the consistency of a research tool that save biasness and free it from error (Guillemin, 2008). There are three prevalent methods of measuring reliability of a questionnaire; test re-tests method, split-half and internal consistency method (Cohen, Manion \& Marrison, 2012). In this study internal consistency method was used to find out reliability of the questionnaire by finding alpha $(\alpha)$ values.

\subsubsection{Reliability of the tool}

The overall reliability of the questionnaire by calculating Cronbach's Alpha $(\alpha)$ value at confidence level 95\% (given in table-1) was found 0.935 as overall on satisfaction and 0.959 on importance. While individual item reliability range was found $0.803-0.816$ on satisfaction and $0.843-0.853$ on importance (Individual item values are given in annexure). All the values are highly appreciating due to having acceptable range Values $\geq 0.70$ is acceptable (Feldmann, List, John \& Bondemark, 2007). 
Table 1 Reliability

\begin{tabular}{l|ll}
\hline \multirow{2}{*}{ Factors } & \multicolumn{2}{|l}{ Range of $\alpha$-value } \\
\cline { 2 - 3 } $\begin{array}{l}\text { Individual } \\
\text { item }\end{array}$ & $\begin{array}{l}\text { Satisfaction } \\
0.803-0.816\end{array}$ & Importance \\
& & $0.843-0.853$ \\
\hline Overall & 0.932 & 0.959 \\
\hline
\end{tabular}

\subsubsection{Individual item reliability; item-to-scale correlation}

It was calculated by item-to-scale correlation and multiple of $r^{2}$ values were calculated. Table- 2 presents the range of calculated values on reliability of the individual items in the research instrument. In the $1^{\text {st }}$ row individual item-scale correlation values have a range on satisfaction is 0.244-0.649 while on importance range of values is $0.312-0.550$ and multiple $r^{2}$ values range on satisfaction is $0.215-525$ while on importance range is $0.206-0.561$.

Table-2 Individual item reliability

\begin{tabular}{l|ll}
\hline \multirow{2}{*}{ Factors } & \multicolumn{2}{|l}{ Range of values } \\
\cline { 2 - 3 } $\begin{array}{l}\text { Individual } \\
\text { item-scale }\end{array}$ & Satisfaction & Importance \\
correlation & $0.244-0.649$ & $0.312-0.550$ \\
\hline Multiple $r^{2}$ values & $0.215-525$ & $0.206-0.561$ \\
\hline
\end{tabular}

All the items in this research tool are reliable with respect to item-scale correlation due to having none of the values less than 0.2 ( $0.2 \geq$ is acceptable value) (Field, 2005; Vernon, Tiro, Vojvodic, Coan, Diamond, Greisinger \& Fernandez, 2008).

It can be concluded that the research tool is reliable with all respects. Now let us see what happened with its' validity.

\subsubsection{Validity of the Questionnaire}

Validity of a research tool measures the accuracy of the tool. It is the degree to which an instrument measures what is supposed to measure (Hinton, 2004; Guillemin, 2008; Anthony, 2011). Therefore, to collect the accurate and concise information research tool should be made valid before using it in a study. With respect to validity, construct validity of this research questionnaire was assured. Construct validity is the relationship of variables that are theoretically 
related to that scale and has to measure in a study (Sirkin, 2006). It measures the arrangement of items and point out either item are in a required sequence or needed replacement or needed to be deleted from the tool. In this study convergent and discriminate validities were measured by calculating Spearman's rho (r) value method.

\subsubsection{Convergent validity}

It measures the relationship between items or statements within a factor. Its values vary with respect to number of items as items increases the correlation becomes strong. It is also said correlation between items falling under one factor and is calculated by finding spearman's rho (r) values (Wagenmakers, Akker-Scheek, Groothoff, Zijlstra, Bulstra, Kootstra, 2008).

The tables-3 shows the convergent validity values calculated by Spearman's rho method. The range of calculated values of inter-item correlation values among individual items is $0.209-0.372$ on satisfaction option and $0.245-0.405$ on importance.

Table 3 Convergent values

\begin{tabular}{l|ll}
\hline \multirow{2}{*}{ Factor } & $\begin{array}{l}\text { Range of Spearman's r-value } \\
\text { between items }\end{array}$ \\
\cline { 2 - 3 } Courses & Satisfaction & Importance \\
\hline & $0.209-$ & $0.245-$ \\
& 0.372 & 0.405 \\
\hline
\end{tabular}

All the values are within acceptable range therefore it can be concluded that the research tool is reliable with respect to inter-item correlation. Let us see what happened in the next step with this tool.

\subsubsection{Discriminate validity}

It is agreement or association among variables in a tool and is calculated by spearman's correlation coefficient value between major variables. It is judged on the basis of whether an indicator corresponds to theoretical expectations in terms of relationships with other variables in a tool (Jie Wang et al., 2011).

There are seven variables in this tool; choices, motivation, reflective thinking, analytical, problem, life-long learning and ICT application items. All the items about the same variable were summed up and Spearman's correlation value among these variables was 
calculated. In the table-4 the range of the values on satisfaction is $0.365-0.571$ and on importance is $0.260-0.636$. All the values are within acceptable range due to having none of the values less than 0.3 (Field, 2005).

Table 4 Discriminate validity

\begin{tabular}{c|ll}
\hline \multirow{2}{*}{ Factor } & \multicolumn{2}{|c}{ Range of Spearman's r-values } \\
\cline { 2 - 3 } & Satisfaction & Importance \\
\hline 9-factors & $0.365-$ & $0.260-$ \\
& 0.571 & 0.636 \\
\hline
\end{tabular}

Therefore, in the case of discriminate validity the questionnaire is valid and ready to use.

\section{Conclusion and Discussion}

Courses are learning material on which all teaching learning activities revolve in an institution therefore considered an important learning facility. Measuring students' satisfaction on this learning facility as well as short comings, students' (who are the users of this facility) suggestions are considered important at university level to overcome its shortcoming. It is also due to that in this era of competition students' demands are considered important to attract them and get the required results to bring the institution into the rank (Marzo-Navarro, Pedraja-Iglesias \& Pilar Rivera-Torres, 2005). In this study a self-developed survey questionnaire was made reliable and valid with the help of SPSS-16. In Pakistani scenario the concept of a reliable and valid instrumentation is rare and most of the researchers only depend on experts opinion as done by Shirazi (2004), Yasmeen (2005), Iqbal (2004), Din (2009) and so on except Ali (2005) who has validated his research tool as well has made it reliable before using in study. While only a reliable and valid tool can give accurate, bias-less and up to the mark information in a study to make conclusions (Best \& Khan, 2006; Cohen, Manion \& Morison, 2012).

In this work it took three steps to finalize the tool final shape that has 19 statements. The final questionnaire was reliable with respect to overall reliability Cronbach's Alpha $(\alpha)$ value as well as individual item reliability. The construct validity with respect to convergent validity was calculated by Spearman's rho method that 
was found within acceptable range. Now the questionnaire is reliable as well as valid therefore ready to use in a study in Pakistan only.

\section{References}

Adair, J. (2007). The art of creative thinking, London: Kogan Page.

Ali, A. (2005). A Study of the Academic Functioning of the Universities in Pakistan ( $\mathrm{PhD}$ Thesis). Sargodha University, Sargodha, Pakistan.

Aldridge, S., \& Rowley, J. (1998). Measuring customer satisfaction in higher education. Quality Assurance In Education, 6(4), 197-204. http://dx.doi.org/10.1108/09684889810242182

Anthony, D. (2011). Statistics for Health, Life and social Sciences. London Business School, Regent's Park

Best, W. J., \& Kahn, V. J. (2006). Research in Education. New Delhi, India: Prentice-Hall of India (Pvt).

Cohen, L., Manion, R., \& Morrison, K. (2012). Research Methods in Education $\left(6^{\text {th }}\right.$ ed). New York: Rutledge.

Corbett, P. (2003). Social Research: Theories, Methods and Practices. Thousand Oak, London: Sage Publishers.

Creswell, J.W. (2009). Understanding Mix Method Research. Thousand Oak, London: Sage Publishers.

Csikszentmihalyi, M (2006). Developing Creativity in Higher Education: Developing creativity (Ed). USA: Routledge.

Din, M. (2009). A Study in Indices of Discrepancy between Students' Learning Styles and Their Actual Grade Achievement at Masters' Level (PhD Thesis). NUML University, Islamabad-Pakistan.

Douglas, J., Douglas, A., \& Barnes, B. (2006). Measuring student satisfaction at a UK university. Quality Assurance in Education, 14(3), 251-267.

Feldmann, I., List, T., John, M., \& Bondemark, L. (2007). Reliability of a Questionnaire Assessing Experiences of Adolescents in Orthodontic Treatment. The Angle Orthodontist, 77(2), 311-317.

Field, A. (2006). Discovering Statistics by Using SPSS. London: Sage Publishers. 
Fraenkle, R. J., Wallen, E. N., \& Hyun, H. H. (2006). How to Design and Evaluate Research in Education. NewYork: McGraw Hill.

Fry, H., Ketteridge, S., \& Marshall, S. (2004). A handbook for teaching \& learning in higher education. New Delhi: Crest Publishing House.

Guillemin, I. (2008). Validity, reliability, and responsiveness of a new short Visual Simplified Respiratory Questionnaire (VSRQ\&copy;) for health-related quality of life assessment in chronic obstructive pulmonary disease. International Journal of Chronic Obstructive Pulmonary Disease, 9. http://dx.doi.org/10.2147/copd.s4325

Hinton, R P. (2004). Statistics Explained ( ${ }^{\text {nd }}$ ed). New York: Routledge Taylor and Francis Group.

Huang, F. (2007). Internationalization of Higher Education in the Developing and Emerging Countries: A Focus on Transnational Higher Education in Asia. Journal of Studies in International Education, 11(3-4), 421-432.

Iqbal, A. (2004). Problems and Prospects of Higher Education in Pakistan (PhD Thesis). Arid University, Rawalpindi, Pakistan.

Jackson, N. (2006). Developing Creativity in Higher Education; imagining a different world. USA: Routledge.

Jie Wang, Yan Cui, Bian, R., Mo, Y., HaiDi Wu, \& Ling Chen. (2011). Validation of the Chinese version of the Walking Impairment Questionnaire in patients with both peripheral arterial disease and type 2 diabetes mellitus. Diabetes and Vascular Disease Research, 8(1), 29-34.

Kember, D., \& Leung, D. (2009). Development of a questionnaire for assessing students' perceptions of the teaching and learning environment and its use in quality assurance. Learning Environments Research, 12(1), 15-29.

Mangubhai, F., Marland, P., Dashwood., A \& Son, B. J. (2007). Framing communicative language teaching for better teacher understanding. Journal of Educational Research, 17(1), 85-106.

Marzo-Navarro, M., Pedraja-Iglesias, M., \& Pilar Rivera-Torres, M. (2005). Measuring customer satisfaction in summer 
courses. Quality Assurance in Education, 13(1), 53-65. http://dx.doi.org/10.1108/09684880510578650

Rubin, A., \& Bubbies, R. E. (2005). Research Methods for Social Work. New York: Sage Publishers.

Shirazi, H. J. M. (2004). Analysis of Examination System at University Level in Pakistan. (PhD Thesis). Arid University, Rawalpindi, Pakistan.

Singh, K. Y., \& Bajpai, B. R. (2007). Research Methodology: Techniques and Trends: APH Publisher.

Sirkin, M. R. (2006). Statistics for the Social Sciences. California: Sage Publication.

Usman, A. (2010). The Impact of Service Quality on Students' Satisfaction in Higher Education Institutes of Punjab. Journal of Management Research, 2(2). http://dx.doi.org/10.5296/jmr.v2i2.418

Utts, J. M., \& Heckard, F.R. (2004). Mind on Statistics. Belmont USA: Thomson Books

Vernon, S., Tiro, J., Vojvodic, R., Coan, S., Diamond, P., Greisinger, A., \& Fernandez, M. (2008). Reliability and Validity of a Questionnaire to Measure Colorectal Cancer Screening Behaviors: Does Mode of Survey Administration Matter?. Cancer Epidemiology Biomarkers \& Prevention, 17(4), 758-767. http://dx.doi.org/10.1158/1055-9965.epi-07-2855

Wagenmakers, R., Akker-Scheek, I., Groothoff, J., Zijlstra, W., Bulstra, S., \& Kootstra, J. et al. (2008). Reliability and validity of the short questionnaire to assess health-enhancing physical activity (SQUASH) in patients after total hip arthroplasty. BMC Musculoskeletal Disorders, 9(1). http://dx.doi.org/10.1186/14712474-9-141

Yasmeen, S (2005). Impact of Higher Education in Understanding of

Social Recognition in Women (PhD Thesis). Arid University, Rawalpindi. 